\title{
Comorbidity Cohort (2C) study: Cardiovascular disease severity and comorbid osteoarthritis in primary care
}

\author{
James A Prior ${ }^{1,2 *}$, Claire A Rushton ${ }^{1}$, Kelvin P Jordan ${ }^{2}$ and Umesh T Kadam,2
}

\begin{abstract}
Background: Two of the commonest chronic diseases experienced by older people in the general population are cardiovascular diseases and osteoarthritis. These conditions also commonly co-occur, which is only partly explained by age. Yet, there have been few studies investigating specific a priori hypotheses in testing the comorbid interaction between two chronic diseases and related health and healthcare outcomes. It is also unknown whether the stage or severity of the chronic disease influences the comorbidity impact. The overall plan is to investigate the interaction between cardiovascular severity groups (hypertension, ischaemic heart disease and heart failure) and osteoarthritis comorbidity, and their longitudinal impact on health and healthcare outcomes relative to either condition alone.

Methods: From ten general practices participating in a research network, adults aged 40 years and over were sampled to construct eight exclusive cohort groups $(n=9,676)$. Baseline groups were defined on the basis of computer clinical diagnostic data in a 3-year time-period (between 2006 and 2009) as: (i) without cardiovascular disease or osteoarthritis (reference group), (ii) index cardiovascular disease groups (hypertension, ischaemic heart disease and heart failure) without osteoarthritis, (iii) index osteoarthritis group without cardiovascular disease, and (vi) index cardiovascular disease groups comorbid with osteoarthritis. There were three main phases to longitudinal follow-up. The first (survey population) was to invite cohorts to complete a baseline postal health questionnaire, with 10 monthly brief interval health questionnaires, and a final 12-month follow-up questionnaire. The second phase (linkage population) was to link the collected survey data to patient clinical records with consent for the 3-year time-period before baseline, during the 12-month survey period and the 12 months after final questionnaire (total 5 years). The third phase (denominator population) was to construct an anonymised clinical data archive for the study five year period for the total baseline cohorts, linking clinical information such as diagnosis, prescriptions and referrals.
\end{abstract}

Discussion: The outcomes of the study will result in the determination of the specific interaction between cardiovascular severity and osteoarthritis comorbidity on the change and progression of physical health status in individuals and on the linked and associated clinical-decision making process in primary care.

Keywords: Comorbidity, Cardiovascular diseases, Osteoarthritis, General practice, Cohort studies

\footnotetext{
* Correspondence: j.a.prior@keele.ac.uk

${ }^{1}$ Health Services Research Unit, Innovation Centre 1, Keele University Science

\& Business Park, Keele University, Staffordshire ST5 5NB, UK

${ }^{2}$ Arthritis Research UK Primary Care Centre, Primary Care Sciences, Keele

University, Staffordshire ST5 5BG, UK
}

\section{Biomed Central




\section{Background}

As people get older, they are more likely to experience a chronic disease, such as cardiovascular disease (CVD) or osteoarthritis (OA), and many will experience two or more chronic diseases at the same time [1]. With increasing life spans, each individual is more likely to experience multiple chronic diseases. Yet, in the day-today management of patients, the focus has often been on single chronic disease [2]. Such approaches do not acknowledge or address the common experience of older populations with multiple chronic diseases such as CVD and OA. Implications for the impact on health care and health care systems lie, for example, in the variations in the clinical decision-making process as exemplified by referrals [3] and in mortality outcomes [4], which could be explained by the presence of multiple chronic diseases in the same individual. It has been argued that the management of single diseases may distort the provision of good health care by not addressing the potential interactions of different conditions and therefore not appropriately assessing the management of each chronic illness in the real clinical situation [5]. Consideration of potential patterns of care in patients with comorbidity requires a broader perspective on management and the clinical pathways, and alternative approaches are required to address this problem [6]. From an international perspective, in an ageing European population, this issue is set to become an increasing public health priority. Current estimates range up to 30 million European sufferers with two or more chronic diseases, with further increases likely as the number of older Europeans expands by an estimated $30 \%$ in the next 25 years [7].

Two of the commonest chronic diseases experienced by older people in the general population are CVD and OA [8]. Cardiovascular disease, shares many of the chronic disease characteristics shown by OA, and is an important cause of disability as well as mortality. A range of studies have shown that CVD is associated with poor physical health, and this relationship influences management progression and health care outcomes. For example, people with poor physical health are likely to report greater CVD health needs [9], the progression of CVD symptoms is likely to be associated with poor physical health [10] and this in consequence is likely to lead to higher hospital admissions and mortality [11]. In a similar pattern to OA, co-existing depression adversely influences symptoms of CVD and is more likely to be associated with poor physical health [12]. Specific studies have also shown that poor physical health is associated with CVD that range from hypertension, atrial fibrillation, angina, myocardial infarction to heart failure. Some studies indicate that poor health in hypertension is unexplained by socio-demographic factors or comorbidity [13], in atrial fibrillation is dependent on the severity of symptoms [14], in angina patients is associated with depression and anxiety [15], and in myocardial infarction or heart failure is associated with poor health care outcomes $[16,17]$.

Osteoarthritis is the most frequent reason for restricted activity in daily life [18] and has a high impact on health care use and costs [19], both in hospital (for example, joint replacements [20]) and in primary care in relation to consultations and drug use [21]. The prevalence of many other disabling conditions also rises with age, and some common chronic conditions can be found alongside OA, including CVD [22]. We have previously shown that there are specific associations in OA sufferers in general practice [23] and that the combination of $\mathrm{OA}$ and comorbidity is associated with much poorer physical health [24]. Several studies have shown that OA and specific CVD are associated together and this co-occurrence is independent of age [25,26]. Explanations for this finding include pathologic links, similar and shared risk factors or intermediary links, such as drugs (anti-inflammatories). In addition to adverse mortality outcomes, previous OA studies have also shown that people with CVD comorbidity have poor quality of life, and that co-existing conditions such as depression can influence similar outcomes $[27,28]$.

In primary care, where multiple morbidity is the rule rather than the exception [29,30], general practitioners and primary care by definition deal with many different morbidities presented by the same individual. As each encounter contributing to multiple morbidity is routinely recorded during consultations and subsequently in historical records, so a catalogue of health states emerges through which an individual passes over time. Such health events might be linked to each other [31], because they represent overlapping syndromes [32] or are a result of shared causes or mechanisms, and their interactions might help to explain different patterns in health course or progression. Studies of multiple morbidity in primary care, based on a limited number of empirically selected chronic conditions, have shown that it is negatively associated with overall health [33] and that it is associated with increased referral to secondary care and increased health care costs [1,34]. Whilst, studies of the association between specific chronic diseases and overall health have been completed, especially in relation to changes within intervention studies, very few studies have examined the patterns of change in health that leads to consultation [35] and in those with specific dual chronic diseases at the same time. How comorbidity influences short and longer-term health status in CVD or OA, how it causes changes in health status, and how it influences health care management decisions is unknown. 
Within the broad terms of CVD or OA, there will be spectrum of different disease categories for each individual chronic disease. So for example, the term 'CVD' encapsulates a spectrum ranging from hypertension to chronic congestive heart failure as outlined, and 'OA' encapsulates a spectrum of joint-specific problems. In each spectrum, each stage implicitly carries the notion of the process of disease severity related to a specific outcome. For example, in people with OA, impact on mobility will be dependent on the joint site and whether there is pain with or without radiographic change, whereas, the stage of CVD will determine outcomes, such as health status and mortality. In the course of chronic disease development in populations, it is the stages within each disease process that offers one definition of 'severity'. Studies, for example, in the CVD field, suggest that the lifetime risk of different CVD varies with age and the related risk factors [36-38]. So instead of simply using broad disease categories, the spectrum of CVD 'severity' potentially offers an empirical way of exploring the disease gradient to investigate whether the interaction between two individual chronic diseases and its impact on health is over and above that which we might expect from simply combining the individual effects.

Using an empirically defined order of disease severity we intend to use hypertension, ischaemic heart disease (angina or myocardial infarction) and heart failure as indicators of CVD severity with comorbid OA defined as a single broad category. In this study we propose to investigate the specific interaction of CVD severity and OA comorbidity on:

(i) the progression of physical health (with the null hypothesis: that the adverse influence on physical health is the same for CVD and comorbid OA compared to those with either index condition alone), and

(ii) the associated clinical decisions in consulting adult general practice populations aged 40 years and over compared to consulters with either condition alone or without either condition (with the null hypothesis: that clinical decisions are the same for CVD and comorbid OA compared to those with either index chronic disease).

\section{Methods}

\section{Setting}

Our study will be carried out in ten general practices, from North Staffordshire, Stoke-on-Trent and Cheshire. These practices are part of a local research network, the Primary Care Musculoskeletal Research Consortium. These practices, supported by the Primary Care Research West Midlands North (PCR WMN) network, cover a wide range of socio-economic groups and includes practices that have actively participated in routine collection of clinical data using computer records for the purposes of epidemiological study. Clinical information relating to all morbidity and drug therapies is recorded using standard classifications of Read codes [39] and BNF (British National Formulary) respectively [40]. Ethics permission was sought and given by the Cheshire Research Ethics Committee (REC ref no: 09/H1017/40).

\section{Study population}

The cohort study is based on the recruitment of four main groups aged 40 years and over who have either a record or consultation for: (i) No CVD or OA (reference); (ii) CVD without OA; (iii) OA without CVD and (iv) CVD and OA (comorbid cohort). The sampling of these groups from the ten general practices was in a three-year period beginning November 2006 and ending January 2010.

\section{Identifying cohort samples}

CVD cohorts: Using the CVD registers and historical information, all adults aged 40 years and over who had a record (main Read code Chapter G: "Cardiovascular system diseases") and on active registration at the end of the 3-year study time-period will be identified. Cohorts will then be based on the three CVD severity categories of hypertension (Read and daughter codes beginning with G20), ischaemic heart disease (Read and daughter codes beginning with G3.) and heart failure (Read and daughter codes beginning with G58 and heart failure codes related New York Heart Association (NYHA) classification), as these conditions are currently part of the national Quality Framework of clinical recording, a means by which General Practitioners (GP) are reimbursed as part of chronic disease management. The CVD groups will be organised into three exclusive severity groups, which means that allocation to a cohort group will be based on the most severe category e.g. if an individual had consulted for hypertension and heart failure, they would be in the heart failure cohort. Previous studies have indicated that the recording quality of such information is likely to be high $[41,42]$. These three cohorts will be separated into two sub-groups of (i) patients who had not consulted for $\mathrm{OA}$ in the same time period (index CVD cohort) and (ii) patients who had also consulted for OA in the same time period (comorbid cohort). All those in the three CVD severity groups who had comorbid OA were sampled, as were those with heart failure or ischaemic heart disease but no OA. However, those with hypertension but without OA were randomly sampled (stratified by practice) given the high prevalence of this group (see Sample size).

$O A$ cohort: Using the general practice records for the same time period (2006-2010), all adults aged 40 years 
and over, who are actively registered and who either have a historical record or consultation for OA (Read and daughter codes beginning with $\mathrm{N} 05$, and codes related to OA joint replacement (7 K2 or $7 \mathrm{~K} 3$ )) will be identified. This cohort group will be exclusive of those patients who had also consulted for any CVD-related diagnosis (as stated above) in the same time period.

Non-index cohort: Using the general practice records for the same time period (2006-2010), a random sample stratified by practice of all adults aged 40 years and over without a historical record or consultation for the study specific CVD and OA codes will be identified. This sample will provide a random reference group for the other main cohort categories.

\section{Data collection}

There are 3 phases to the study data collection. The first phase (survey population) will use postal questionnaires to obtain self-reported health information at baseline, monthly interval and 12-month follow-up. The second phase (linkage population) will link the survey data to consultation data, for patients who will give written consent to access their clinical records from general practice in the baseline questionnaire. The third phase (denominator population) will construct an anonymised database for the whole cohort for the total five-year time-period. So the denominator cohort constitutes the whole sample from which the survey sample will be drawn. The denominator sample will provide the basis for a distinct cohort sample in its own right, as well as addressing selection comparisons between people who took part in the survey and those who did not, and people who gave consent to record review and who did not.

\section{Phase 1: Survey population}

Overall, study participants will be invited to complete 12 questionnaires - baseline and 12-month follow up, and between these time-points, 10 monthly shortinterval questionnaires (Figure 1). A pilot study in one practice on 500 patients was carried out to test the feasibility of sampling and testing of the questionnaire methods.

\section{Baseline survey}

The identified sampled cohorts will be sent a baseline questionnaire (Q1), which will include generic and specific-health measures (Table 1). Measures have been identified on the basis of the primary focus on CVD and OA diseases and other specific measures selected on the basis of conceptual links between the disease and outcome of interest in the follow-up phase.

For the primary outcome of interest, we will use the Short-Form-12 (SF-12) (version 2) health survey as a generic measure of physical health, specifically the Physical Component Summary (PCS) score [43]. We will also include an assessment of physical activity [44] and Hospital Anxiety and Depression (HAD) questionnaire will be included as a measure of psychological status, that influences both CVD and OA [45].

The CVD-specific measures will include the: Seattle Angina Questionnaire [46], Kansas City Cardiomyopathy

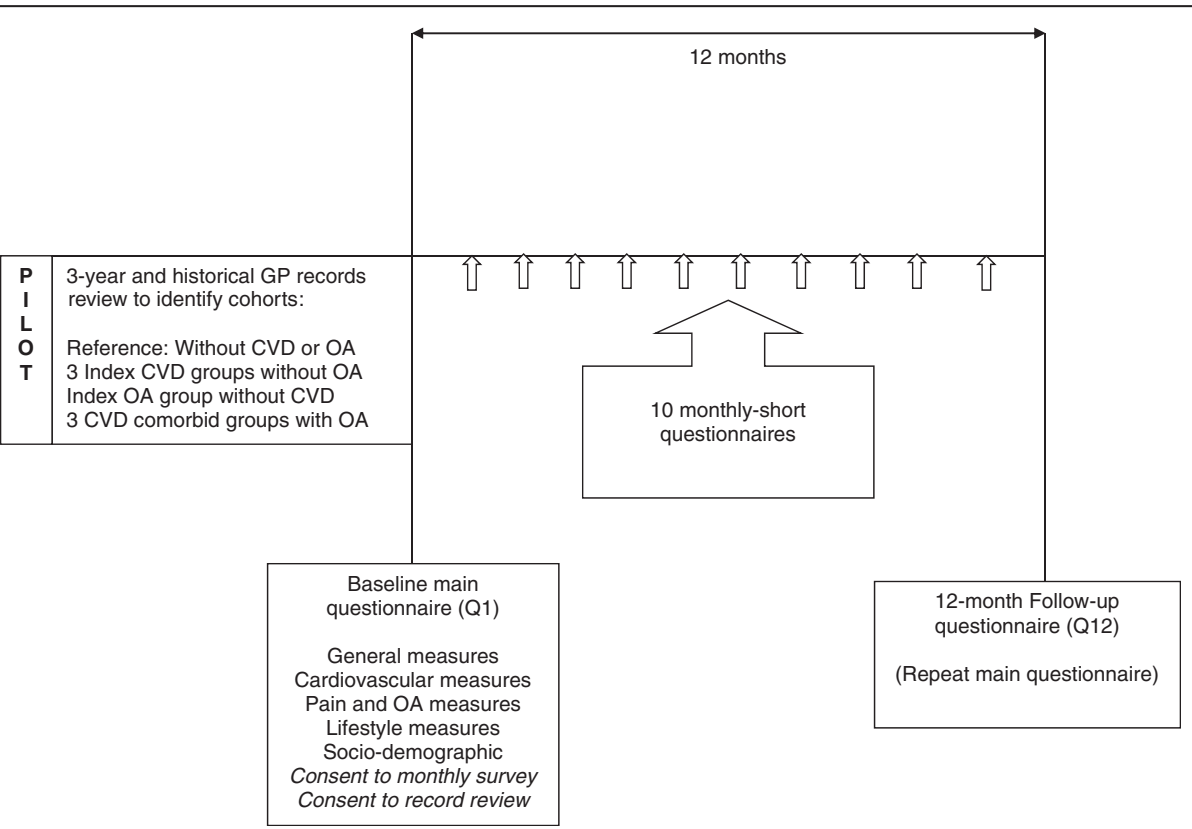

Figure $12 \mathrm{C}$ study design. 
Table 1 Comorbidity Cohort (2C) study measures

\begin{tabular}{|c|c|c|c|}
\hline \multirow[b]{2}{*}{ Data source } & \multirow[b]{2}{*}{ Factors } & \multicolumn{2}{|l|}{ Survey measures } \\
\hline & & Baseline \& 12-month follow-up & Short monthly** \\
\hline \multirow[t]{5}{*}{ Clinical records } & 8 disease cohorts & - Read code classification* & \\
\hline & Consultation comorbidity & - Kadam severity classification & \\
\hline & Blood tests \& investigations & - Read code classification* & \\
\hline & Drugs prescribed & . British National Formulary (BNF) & \\
\hline & Referrals & - Read code classification* & \\
\hline \multirow[t]{24}{*}{ Survey data } & General measures & . Short form 12 (SF-12) health survey & . SF-12 \\
\hline & & . Short form 36 (SF-36) health survey - Q2 only & · SF-36, Q2 \\
\hline & & · EuroQol (EQ-5D) & \\
\hline & & - Hospital Anxiety and Depression (HAD) scale & \\
\hline & & - Medical Outcomes Study (MOS) - Sleep Scale & . Qs 1 \& 2 only \\
\hline & & - Functional Assessment of Chronic Illness (FACIT) - & - Qs 5 \& 6 only \\
\hline & & Fatigue & \\
\hline & & - Brief Illness Perception Questionnaire (B-IPQ) & \\
\hline & & - Social Networks & \\
\hline & Cardiovascular measures & - Seattle Angina Questionnaire (SAQ), UK version & - Qs 2 \& 3 only \\
\hline & & - Kansas City Cardiomyopathy Questionnaire (KCCQ) & . Qs 3 \& 7 only \\
\hline & & - Rose Angina Questionnaire & \\
\hline & & - Palpitations (based on [50]) & - Q1 only \\
\hline & & - Vertigo Severity Scale (VSS) & - Q1 only \\
\hline & Pain and $O A$ measures & - Pain manikin, pain frequency \& pain intensity & . Pain frequency \\
\hline & & - Knee Injury \& Osteoarthritis Outcome Score (KOOS) - & \\
\hline & & Physical Function Shortform & \\
\hline & & - Hip Injury \& Osteoarthritis Outcome Score (HOOS) - & \\
\hline & & Physical Function Shortform & \\
\hline & Lifestyle & · Body Mass Index (BMI), Alcohol, Smoking & \\
\hline & & - Short Questionnaire to Assess Health Enhancing & - Qs 2a, 2c, 2e only \\
\hline & & Physical Activity (SQUASH) & \\
\hline & Other & · Eyesight/hearing & \\
\hline & & - Body shape & \\
\hline Survey \& clinical records & Socio-demographic & - Age, Gender, Deprivation & \\
\hline
\end{tabular}

*Read code classification is a standard clinical coding system used in British general practice; ${ }^{* *}$ question numbers refer to the original questionnaire.

questionnaire [47], Rose angina questionnaire [48], and symptoms of palpitations [49] and dizziness [50].

The OA-specific measures will include the: Knee injury and Osteoarthritis Outcome Score (KOOS - physical function component) [51], Hip injury and Osteoarthritis Outcome Score (HOOS - physical function component) [52], pain scale, pain manikin [53], joint pain, and other links previously reported in chronic disease literature in relation to the symptoms of tiredness [54] and sleep [55].

Survey participants will also be requested for consent to the monthly short-interval questionnaires and for permission to the subsequent review of their clinical records. Participants will be "tagged" in their general practice registers as ' $2 \mathrm{C}$ ' study participants.
Measurement of health in the 12-month follow-up period With baseline consent, participants will be sent 10 monthly short-interval questionnaires (4 pages), including the SF-12, pain measures and CVD symptom measures. At the end of the study period, all study participants will be sent a 12-month follow-up postal questionnaire (Q12) using the same measures as used in the baseline survey.

\section{Phase 2: Survey-consultation linkage population}

The linked consultation data covers a total five-year time-period, for 3 years before the baseline survey, 12 months of the survey, and the 12 months after the full follow-up survey. We will measure the clinical 
(GP or nurse) decision process associated with the survey cohort follow-up. Using the same study samples for both phases allows the linkage of the self-reported health status, morbidity and the decision process experienced by that individual patient in the 12 -month period.

After the completion of the survey phase, the clinical record data for cohort groups will be downloaded with prior patient consent. Clinical decisions in consenting patients will be measured following the baseline survey on the basis of: (i) drug treatment changes (new, repeat, dose, type), (ii) investigations such as blood tests or X-rays, (iii) referrals (in-practice and external, investigation or second-opinion) or (iv) no change in any of these measures. Drug use will be measured on the basis of new index-related treatments (i.e. analgesia for OA and CVD-related therapies), or change in doses used for those on pre-existing drug treatments. Investigations will cover index-specific indications, cardiological (e.g. Electrocardiogram (ECG), Cholesterol) or rheumatological (e.g. X-Rays). Referrals will include those relevant to the index conditions (i.e. physiotherapists and allied therapists, rheumatologists, orthopaedics and cardiologists) and all other referrals. Other measurements for the cohorts will include all other comorbidity using the Kadam severity classification [56,57], specific morbidities such as cerebrovascular disease and peripheral arterial disease, and co-drug therapies used.

\section{Phase 3: Anonymised denominator population}

Phase 1, survey population method is defined by the responders who take part in the study, phase 2 , the survey-consultation method is subject to the consenters who will give permission for this link to occur. Therefore, phase 3 will focus on the total cohort denominator population and the anonymised clinical data within the medical records of each individual patient to allow methodological assessment of response biases in the cohort samples. Patients who explicitly stated to their general practice that they did not wish to take part in any research or share their clinical data are excluded from this phase.

For the total denominator population, invited to take part at baseline, anonymised clinical data with patient diagnostic information, prescribed drugs, blood tests and investigations, referrals and linked healthcare activity will be collected. This anonymised data archive covers a total five year time-period (between 2006 and 2011) from 3 years prior to the baseline survey to 12 months after the 12 month follow-up survey (Figure 2).

\section{Sample size}

The pilot study was used to guide the sample size needed. The primary outcome of the study is the mean change in PCS score from baseline to 12-month follow- up. In order to compare the change in PCS score between the whole comorbid (OA and CVD) cohort and the OA index cohort we estimated that at least 394 patients responding at 12 months per cohort were needed (confidence level 0.05 ; power $80 \%$ ) to detect a between cohort effect size of 0.2 . Based on expected responses of $60 \%$ at baseline and $70 \%$ at 12 months, this required 939 patients to be invited with comorbid OA and CVD and 939 with OA alone. Assuming 75\% consent to medical record review, this number would also give 423 people in each cohort responding at baseline and consenting to record review. However, to maximize numbers in the index CVD cohorts (hypertension, ischaemic heart disease and heart failure), OA index and comorbid groups and in order to allow comparison between the CVD severity comorbid cohorts with their related index CVD cohorts, we invited all eligible patients with these conditions to participate. The exceptions were the index hypertension cohorts and index OA cohorts where we randomly sampled patients stratified by practice due to the large size of these groups. Similarly, we also randomly sampled patients from the reference group without CVD or OA.

\section{Analysis}

\section{Phase 1: Survey population}

The initial analysis will use independent t-tests to compare the OA and CVD comorbid cohorts with mean change in PCS over the 12-month period. We will then examine the influence of CVD severity, comorbidity and baseline covariates on mean change in PCS score using multiple linear regression methods, including cohort group, anxiety and depression, Body Mass Index (BMI), and socio-demographic characteristics (i.e. age, gender, neighborhood level deprivation [58]) as explanatory variables. These analyses will be repeated with change in the Mental Summary Component (MCS) score of the SF-12 as the outcome.

The monthly PCS scores from the SF-12 will be used as time-dependent repeated outcomes in the 12-month follow up period, to determine the association of baseline measures and time on monthly PCS score. This analysis will use repeated measures multilevel modelling, with a 2-level model (repeated PCS score within patients) with the same explanatory variables as for the 12-month analysis.

\section{Phase 2: Survey-consultation linkage}

We will also determine cumulative onset of disability defined on the basis of the generic and disease-specific health measures. The rate of progression to severe disability in the comorbid groups will be estimated compared to the other groups using Cox regression. Attributable fractions for health status and clinical 


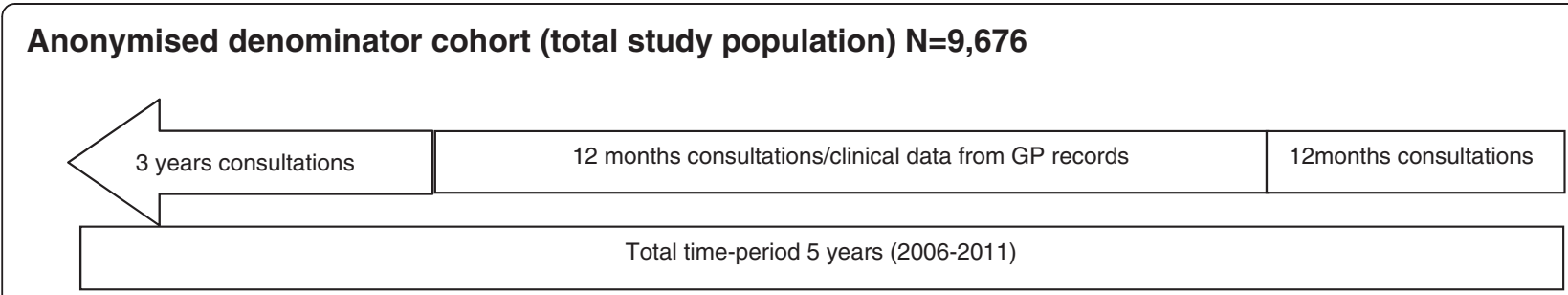

Survey responders cohort $n=5,426$

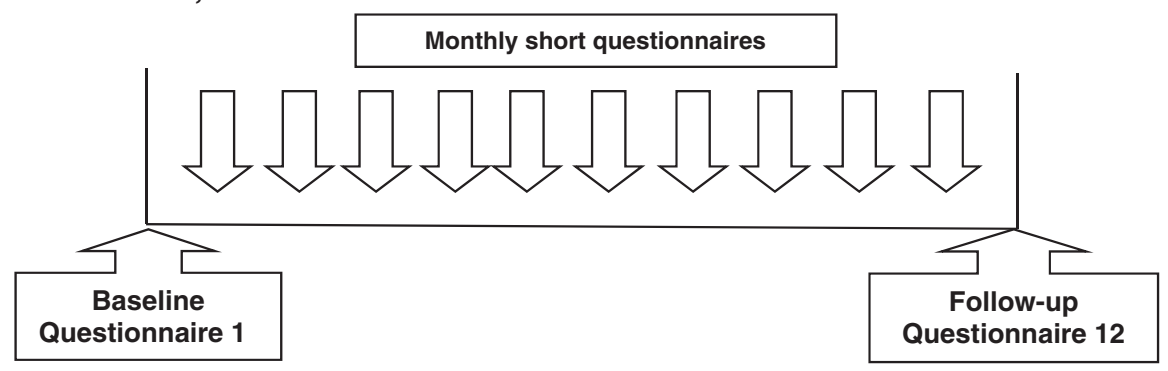

Survey-consultation linkage consenters cohort $n=4,030$

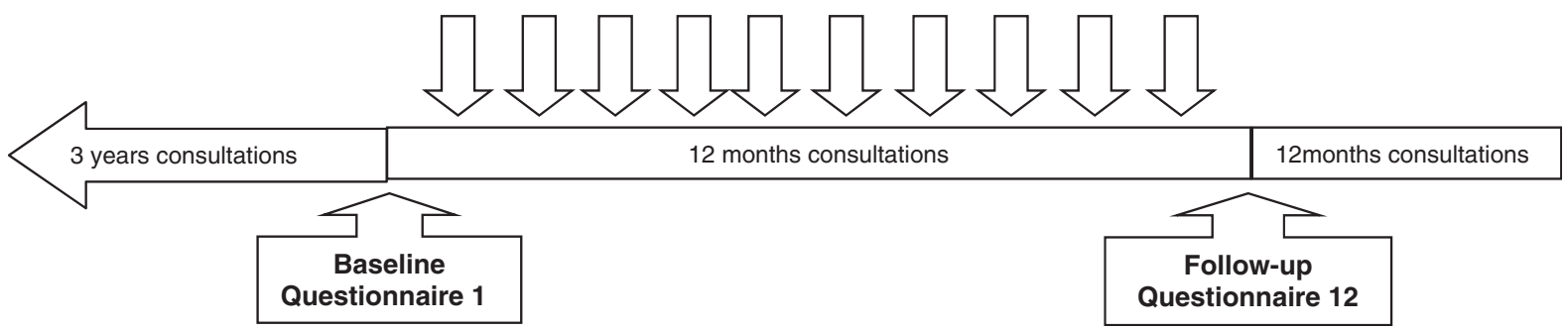

Figure 2 Comorbidity Cohort (2C) design.

decisions (referrals and drug use), and other variables (age, gender, deprivation, obesity, consultation comorbidity) for onset or progression of disability will be determined. We will also assess time to change in clinical decisions.

\section{Phase 3: Denominator population}

We will compare consultation patterns and management for the anonymised denominator cohort to the surveyconsultation cohort to assess generalisability of our findings and estimate the likely extent of response bias.

\section{Preliminary data}

Initial data collection has already been completed and the following data is presented to follow the sequence of sampling stages in an epidemiological cohort study (Figure 2).

\section{Denominator population}

In the denominator cohort population, there were 9,676 people aged 40 years and over (Table 2) who were identified as baseline participants. The denominator study groups were as follows: 2,535 (26\%) without CVD or OA; CVD index groups without OA - 1,322 (14\%) with hypertension, 2,036 (21\%) with ischaemic heart disease, 259 (3\%) with heart failure; 1,317 (13\%) in OA index group without CVD, and CVD groups with comorbid OA 1,644 (17\%) with hypertension, 490 (5\%) with ischaemic heart disease, 73 with heart failure (1\%).

Reference cohort: The reference cohort without CVD or OA (Table 3) was composed of the younger population, and around $69 \%$ were aged 59 years or younger. It had an equivalent number of men and women, and around $20 \%$ in the top or bottom tertiles of deprivation.

Index CVD cohorts without $O A$ : The youngest age groups were in the hypertension cohort $(30 \%$ aged 59 years and younger), and the oldest groups were in the heart failure cohort (69\% aged 70 years and over) (Table 3). There were more men than women in both the IHD and heart failure cohorts, and a quarter of the heart failure cohort had the most deprived status. 
Table $22 \mathrm{C}$ baseline cohorts

\begin{tabular}{|c|c|c|c|c|c|}
\hline $\begin{array}{l}\text { Disease } \\
\text { cohort }\end{array}$ & $\begin{array}{l}\text { Cohort } \\
\text { ID }\end{array}$ & $\begin{array}{l}\text { Denominator cohort } \\
N=9676 n\end{array}$ & $\begin{array}{l}\text { Responders cohort } \\
n=5426 n^{*}(\%)\end{array}$ & $\begin{array}{l}\text { Non-responders } \\
\text { cohort } n=4250 \\
n^{*}(\%)\end{array}$ & $\begin{array}{l}\text { Linkage consenters } \\
\text { cohort } n=4030 \\
n^{* *}(\%)\end{array}$ \\
\hline -CVD -OA & 0 & 2535 & 1165 (45.9) & $1370(54.1)$ & $820(70.4)$ \\
\hline+ Hyp -OA & 1 & 1322 & $720(54.5)$ & $602(45.5)$ & $525(72.9)$ \\
\hline$+\mathrm{HD}-\mathrm{OA}$ & 2 & 2036 & $1196(58.7)$ & 840 (41.3) & 915 (76.5) \\
\hline$+\mathrm{HF}-\mathrm{OA}$ & 3 & 259 & $149(57.5)$ & $110(42.5)$ & $108(72.5)$ \\
\hline$-C V D+O A$ & 4 & 1317 & $828(62.9)$ & 489 (37.1) & 617 (74.5) \\
\hline$+\mathrm{Hyp}+\mathrm{OA}$ & 5 & 1644 & $1017(61.9)$ & $627(38.1)$ & $773(76.0)$ \\
\hline$+\mathrm{HD}+\mathrm{OA}$ & 6 & 490 & $305(62.2)$ & $185(37.8)$ & $237(77.8)$ \\
\hline$+\mathrm{HF}+\mathrm{OA}$ & 7 & 73 & $46(63.0)$ & $27(37.0)$ & $35(76.1)$ \\
\hline
\end{tabular}

$\mathrm{CVD}=$ Cardiovascular disease, $\mathrm{OA}=$ Osteoarthritis, $\mathrm{Hyp}=$ Hypertension, IHD = Ischaemic heart disease, $\mathrm{HF}=$ Heart failure.

Disease categories (defined by study specific Read codes in the 3 years prior to baseline survey.

$-C V D-O A=$ no record of CVD (hypertension, IHD or HF) condition or OA; -CVD + OA = record of OA but not CVD (hypertension, IHD or HF).

$+\mathrm{Hyp}-\mathrm{OA}=$ record of hypertension without $\mathrm{OA} ;+\mathrm{HHD}-\mathrm{OA}=$ record of IHD without $\mathrm{OA} ;+\mathrm{HF}-\mathrm{OA}=$ record of HF without $\mathrm{OA}$.

$+\mathrm{Hyp}+\mathrm{OA}=$ record of hypertension and $\mathrm{OA} ;+\mathrm{HD}+\mathrm{OA}=$ record of IHD and $\mathrm{OA} ;+\mathrm{HF}+\mathrm{OA}=$ record of $\mathrm{HF}$ and $\mathrm{OA}$.

*percentage of denominator population; **percentage of responder population.

Index OA cohort without CVD: Most of this cohort was aged between 50 and 80 years of age, and there were more women than men (Table 3). The age figures were in contrast to the index CVD cohorts who had a higher number in the age group 70 years and over, but the deprivation figures were similar.

Comorbid CVD \& OA cohort: The comorbid groups were relatively older than the index groups and the age proportion for the group 70 years and over were: $57 \%$ in the hypertension comorbid group, $73 \%$ in the IHD comorbid group and $93 \%$ in the heart failure comorbid group (Table 3). There were more women than men with CVD and comorbid OA for all three groups, and IHD comorbid group had relatively fewer numbers in the top and bottom deprivation tertiles.

\section{Survey participation and consent}

In the baseline survey population, there were 5,426 (56\%) people aged 40 years and over who responded to the questionnaire. The lowest response was in the reference cohort (46\%) and the highest was in the comorbid heart failure cohort (63\%). The proportion of responders in the index OA cohort and the CVD comorbid cohorts were higher than the index CVD cohorts (Table 2).

Table 3 Socio-demographic characteristics of the $2 \mathrm{C}$ study denominator population $(\mathrm{n}=9,676)$

\begin{tabular}{|c|c|c|c|c|c|c|c|c|c|}
\hline \multirow[b]{3}{*}{ Factors } & & \multicolumn{8}{|c|}{ Disease cohorts } \\
\hline & & \multirow{2}{*}{$\begin{array}{l}\text { Reference } \\
\text {-CVD -OA (0) } \\
n=2535 \\
(\%)\end{array}$} & \multicolumn{3}{|c|}{ Index CVD cohorts } & \multirow{2}{*}{$\begin{array}{l}\text { Index OA cohort } \\
-C V D+O A(4) \\
n=1317 \\
(\%)\end{array}$} & \multicolumn{3}{|c|}{ CVD comorbid cohorts } \\
\hline & & & $\begin{array}{l}\text { +Hyp -OA (1) } \\
n=1322 \\
(\%)\end{array}$ & $\begin{array}{l}+ \text { +IHD -OA (2) } \\
\mathrm{n}=2036 \\
(\%)\end{array}$ & $\begin{array}{l}+\mathrm{HF}-\mathrm{OA}(3) \\
n=259 \\
(\%)\end{array}$ & & $\begin{array}{l}\text { +Hyp + OA (5) } \\
n=1644 \\
(\%)\end{array}$ & $\begin{array}{l}+\mathrm{IHD}+\mathrm{OA}(6) \\
\mathrm{n}=490 \\
(\%)\end{array}$ & $\begin{array}{l}+\mathrm{HF}+\mathrm{OA}(7) \\
n=73 \\
(\%)\end{array}$ \\
\hline \multirow{5}{*}{$\begin{array}{l}\text { Age group } \\
\text { (years) }\end{array}$} & $40-49$ & $892(35.2)$ & $106(8.0)$ & $72(3.5)$ & $5(1.9)$ & $138(10.4)$ & $33(2.0)$ & $4(0.8)$ & $0(0)$ \\
\hline & $50-59$ & $848(33.5)$ & $291(22.0)$ & $275(13.5)$ & $22(8.5)$ & $309(23.5)$ & $172(10.4)$ & $22(4.5)$ & $1(1.4)$ \\
\hline & $60-69$ & $513(20.2)$ & $416(31.5)$ & $617(30.3)$ & $54(20.8)$ & $445(33.8)$ & $499(30.4)$ & $106(21.7)$ & $4(5.5)$ \\
\hline & $70-79$ & $195(7.7)$ & $329(24.9)$ & $677(33.3)$ & $82(31.7)$ & $278(21.1)$ & $554(33.7)$ & $203(41.4)$ & $23(31.5)$ \\
\hline & $80 \geq$ & $87(3.4)$ & 180 (13.6) & $395(19.4)$ & $96(37.1)$ & $147(11.2)$ & $386(23.5)$ & $155(31.6)$ & $45(61.6)$ \\
\hline \multirow[t]{2}{*}{ Gender } & Men & $1245(49.1)$ & $609(46.1)$ & $1334(65.5)$ & $142(54.8)$ & $563(42.7)$ & $611(37.2)$ & $205(41.8)$ & $31(42.5)$ \\
\hline & Women & $1290(50.9)$ & $713(53.9)$ & $702(34.5)$ & $117(45.2)$ & $754(57.3)$ & $1033(62.8)$ & $285(58.2)$ & $42(57.5)$ \\
\hline \multirow[t]{3}{*}{$\begin{array}{l}\text { Deprivation } \\
\text { Status* }\end{array}$} & $\begin{array}{l}\text { Category } 0 \\
\text { (most } \\
\text { affluent) }\end{array}$ & $525(20.8)$ & $266(20.2)$ & $368(18.1)$ & $38(14.7)$ & $267(20.3)$ & $327(20.0)$ & $86(17.7)$ & $13(18.3)$ \\
\hline & Category 1 & $1521(60.1)$ & $786(59.8)$ & $1251(61.6)$ & $156(60.2)$ & 808 (61.6) & $980(60.0)$ & $310(63.9)$ & $43(60.6)$ \\
\hline & $\begin{array}{l}\text { Category } 2 \\
\text { (most } \\
\text { deprived) }\end{array}$ & $484(19.1)$ & $263(20.0)$ & $411(20.3)$ & $65(25.1)$ & $237(18.1)$ & $327(20.0)$ & 89 (18.4) & $15(21.1)$ \\
\hline
\end{tabular}


Table 4 Socio-demographic characteristics of baseline responders stratified by study groups $(n=5,426)$

\begin{tabular}{|c|c|c|c|c|c|c|c|c|c|}
\hline \multirow[b]{3}{*}{ Factors } & & \multicolumn{8}{|c|}{ Disease cohorts } \\
\hline & & \multirow{2}{*}{$\begin{array}{l}\text { Reference } \\
\text {-CVD -OA (0) } \\
n=1165 \\
(\%)\end{array}$} & \multicolumn{3}{|c|}{ Index CVD cohorts } & \multirow{2}{*}{$\begin{array}{l}\text { Index OA cohort } \\
-C V D+O A(4) \\
n=828 \\
(\%)\end{array}$} & \multicolumn{3}{|c|}{ CVD comorbid cohorts } \\
\hline & & & $\begin{array}{l}\text { +Hyp -OA (1) } \\
n=720 \\
(\%)\end{array}$ & $\begin{array}{l}\text { +IHD -OA (2) } \\
\mathrm{n}=1196 \\
(\%)\end{array}$ & $\begin{array}{l}+\mathrm{HF}-\mathrm{OA} \mathrm{(3)} \\
n=149 \\
(\%)\end{array}$ & & $\begin{array}{l}\text { +Hyp + OA (5) } \\
n=1017 \\
(\%)\end{array}$ & $\begin{array}{l}+\mathrm{lHD}+\mathrm{OA}(6) \\
\mathrm{n}=305 \\
(\%)\end{array}$ & $\begin{array}{l}+\mathrm{HF}+\mathrm{OA}(7) \\
\mathrm{n}=46 \\
(\%)\end{array}$ \\
\hline \multirow{5}{*}{$\begin{array}{l}\text { Age group } \\
\text { (years) }\end{array}$} & $40-49$ & $313(26.8)$ & $33(4.6)$ & $21(1.7)$ & $3(2.0)$ & $59(7.1)$ & $9(0.9)$ & $1(0.3)$ & $0(0)$ \\
\hline & $50-59$ & $413(35.5)$ & $132(18.3)$ & 127 (10.6) & $9(6.1)$ & $180(21.7)$ & $92(9.0)$ & $11(3.6)$ & $0(0)$ \\
\hline & $60-69$ & $282(24.2)$ & $239(33.2)$ & 369 (30.9) & $26(17.4)$ & $312(37.7)$ & $318(31.3)$ & $64(21.0)$ & $3(6.5)$ \\
\hline & $70-79$ & $119(10.2)$ & $219(30.4)$ & $446(37.3)$ & $53(35.6)$ & $180(21.8)$ & $369(36.3)$ & $136(44.6)$ & $16(34.8)$ \\
\hline & $80 \geq$ & $38(3.3)$ & $97(13.5)$ & $233(19.5)$ & $58(38.9)$ & $97(11.7)$ & $229(22.5)$ & $93(30.5)$ & $27(58.7)$ \\
\hline \multirow[t]{2}{*}{ Gender } & Men & $547(47.0)$ & $324(45.0)$ & $807(67.5)$ & $89(59.7)$ & $332(40.1)$ & $391(38.4)$ & $140(45.9)$ & $23(50.0)$ \\
\hline & Women & $618(53.0)$ & $395(55.0)$ & $389(32.5)$ & $60(40.3)$ & $496(59.9)$ & $626(61.6)$ & $165(54.1)$ & $23(50.0)$ \\
\hline \multirow[t]{3}{*}{$\begin{array}{l}\text { Deprivation } \\
\text { Status* }\end{array}$} & $\begin{array}{l}\text { Category } 0 \\
\text { (most } \\
\text { affluent) }\end{array}$ & $279(24.0)$ & $155(21.7)$ & $243(20.4)$ & $23(15.4)$ & $168(20.4)$ & $222(22.0)$ & $59(19.6)$ & $8(18.2)$ \\
\hline & Category 1 & $712(61.2)$ & $425(59.4)$ & $732(61.4)$ & $90(60.4)$ & $521(63.2)$ & 605 (59.9) & $190(63.1)$ & 27 (61.3) \\
\hline & $\begin{array}{l}\text { Category } 2 \\
\text { (most } \\
\text { deprived) }\end{array}$ & $173(14.8)$ & 135 (18.9) & $217(18.2)$ & $36(24.2)$ & $135(16.4)$ & $183(18.1)$ & $52(17.3)$ & $9(20.5)$ \\
\hline
\end{tabular}

$\mathrm{CVD}=$ Cardiovascular disease, $\mathrm{OA}=$ Osteoarthritis, Hyp = Hypertension, IHD = Ischaemic heart disease, HF = Heart failure. *Deprivation status is based on Index of Multiple Deprivation score and available for 5,399 patients and 'most affluent' as the top $20 \%$ of the sample and 'most deprived' as the bottom $20 \%$ of the sample.

The survey responders were broadly similar in terms of age, gender and deprivation characteristics, compared to the denominator population (Table 3 and 4). When comparing the responder and non-responder groups (Tables 4 and 5), non-responders were likely to be the younger groups, women and those people with the most deprived status. In the reference cohort, $74 \%$ of the non- responder group were 59 years or younger. The age proportions of the index hypertension and index OA cohort were similar, but the proportions of age groups 70 years and over were higher in index IHD (47\%) and heart failure (61\%) cohorts, and highest in the IHD (70\%) and heart failure (93\%) comorbid cohorts. Apart from the reference cohort and the index IHD cohort, there were

Table 5 Socio-demographic characteristics of baseline non-responders stratified by study groups $(n=4,250)$

\begin{tabular}{|c|c|c|c|c|c|c|c|c|c|}
\hline \multirow[b]{3}{*}{ Factors } & & \multicolumn{8}{|c|}{ Disease cohorts (Cohort ID) } \\
\hline & & \multirow{2}{*}{$\begin{array}{l}\text { Reference } \\
\text {-CVD -OA (0) } \\
n=1370 \\
(\%)\end{array}$} & \multicolumn{3}{|c|}{ Index CVD groups } & \multirow{2}{*}{$\begin{array}{l}\text { Index OA Groups } \\
-C V D+O A(4) \\
n=489 \\
(\%)\end{array}$} & \multicolumn{3}{|c|}{ CVD comorbid groups } \\
\hline & & & $\begin{array}{l}\text { +Hyp -OA (1) } \\
n=602 \\
(\%)\end{array}$ & $\begin{array}{l}+ \text { IHD -OA (2) } \\
n=840 \\
(\%)\end{array}$ & $\begin{array}{l}+\mathrm{HF}-\mathrm{OA}(3) \\
\mathrm{n}=110( \\
\%)\end{array}$ & & $\begin{array}{l}+ \text { +Hyp + OA (5) } \\
n=627 \\
(\%)\end{array}$ & $\begin{array}{l}+\mathrm{IHD}+\mathrm{OA}(6) \\
\mathrm{n}=185 \\
(\%)\end{array}$ & $\begin{array}{l}+\mathrm{HF}+\mathrm{OA} \mathrm{7)} \\
\mathrm{n}=27 \\
(\%)\end{array}$ \\
\hline \multirow{5}{*}{$\begin{array}{l}\text { Age group } \\
\text { (years) }\end{array}$} & $40-49$ & $579(42.2)$ & $73(12.1)$ & $51(6.1)$ & $2(1.8)$ & $79(16.2)$ & $24(3.8)$ & $3(1.6)$ & $0(0)$ \\
\hline & $50-59$ & $435(31.8)$ & $159(26.4)$ & $148(17.6)$ & $13(11.8)$ & $129(26.4)$ & $80(12.8)$ & $11(5.9)$ & $1(3.7)$ \\
\hline & $60-69$ & $231(16.9)$ & $177(29.4)$ & $248(29.5)$ & $28(25.5)$ & $133(27.2)$ & $181(2.9)$ & $42(22.7)$ & $1(3.7)$ \\
\hline & $70-79$ & $76(5.5)$ & $110(18.3)$ & $231(27.5)$ & $29(26.4)$ & $98(20.0)$ & $185(29.5)$ & $68(36.8)$ & $7(25.9)$ \\
\hline & $80 \geq$ & 49 (3.6) & $83(13.8)$ & $162(19.3)$ & $38(34.5)$ & $50(10.2)$ & $157(25.0)$ & $61(33.0)$ & $18(66.7)$ \\
\hline \multirow[t]{2}{*}{ Gender } & Men & $698(50.9)$ & $285(47.3)$ & $527(62.7)$ & $53(48.2)$ & $231(47.2)$ & $220(35.1)$ & $65(35.1)$ & $8(29.6)$ \\
\hline & Women & $672(49.1)$ & $317(52.7)$ & $313(37.3)$ & $57(51.8)$ & $258(52.8)$ & $407(64.9)$ & $120(64.9)$ & $19(70.4)$ \\
\hline \multirow[t]{3}{*}{$\begin{array}{l}\text { Deprivation } \\
\text { Status* }\end{array}$} & $\begin{array}{l}\text { Category } 0 \\
\text { (most } \\
\text { affluent) }\end{array}$ & $246(18.0)$ & $111(18.5)$ & $125(14.9)$ & 15 (13.6) & $99(20.3)$ & 105 (16.8) & $27(14.7)$ & $5(18.5)$ \\
\hline & Category 1 & 809 (59.2) & $361(60.2)$ & 519 (61.9) & $66(60.0)$ & $287(58.8)$ & $375(60.1)$ & $120(65.2)$ & $16(59.3)$ \\
\hline & $\begin{array}{l}\text { Category } 2 \\
\text { (most } \\
\text { deprived) }\end{array}$ & $311(22.8)$ & $128(21.3)$ & $194(23.2)$ & 29 (26.4) & $102(20.9)$ & $144(23.1)$ & $37(20.1)$ & $6(22.2)$ \\
\hline
\end{tabular}


more women than men non-responders, and around a quarter of the most deprived groups were nonresponders in all study cohorts.

Of the survey responders, 4,030 (74\%) gave permission to access and link their clinical records (Table 2), and this linked clinical data will be anonymised for the purposes of analyses. The lowest consent proportion was in the reference group (70\%) and the highest in the CVD comorbid groups (76\%).

\section{Discussion}

There are very few comorbidity cohort studies [59] and this is the first study of its kind which has been constructed with a priori hypotheses, identifying two common chronic diseases (CVD and OA) in the general practice population, and testing their interaction in relation to self-reported health and health care outcomes. The innovative epidemiological design incorporates comorbid interaction, interaction as influenced by severity (in this example of CVD), and potential cohort impact both in the short-term and longer-term. The innovative methodological design also incorporates a denominator cohort, from which a survey population was sampled, allowing the assessment of selection and data issues. The linkage between survey data and consultation data provides the investigation of population symptoms and health, and their impact on short and longer-term healthcare outcomes.

\begin{abstract}
Abbreviations
2C: Comorbidity Cohort study; B-IPQ: Brief Illness Perception Questionnaire; BMI: Body Mass Index; BNF: British National Formulary; CVD: Cardiovascular Disease; ECG: Electrocardiogram; EQ-5D: EuroQol; FACIT: Functional Assessment of Chronic Illness; GP: General Practitioners; HAD: Hospital Anxiety and Depression questionnaire; HF: Heart Failure; HOOS: Hip injury and Osteoarthritis Outcome Score (physical function component): Hyp: Hypertension; IHD: Ischaemic Heart Disease; KCCQ: Kansas City Cardiomyopathy Questionnaire; KOOS: Knee injury and Osteoarthritis Outcome Score (physical function component); MCS: Mental Component Summary score; MOS: Medical Outcomes Study: OA: Osteoarthritis; PCR WMN: Primary Care Research West Midlands North network; PCS: Physical Component Summary score; REC: Research Ethics Committee; SAQ: Seattle Angina Questionnaire; SQUASH: Short Questionnaire to Assess Health Enhancing Physical Activity; SF-12: Short-Form 12; SF-36: Short-Form 36; VSS: Vertigo Severity Scale.
\end{abstract}

\section{Competing interests}

The authors declare that they have no competing interests.

\section{Authors' contributions}

JAP coordinated the $2 \mathrm{C}$ study, was involved in its development, analysed and interpreted the data and contributed to the writing of this manuscript. CAR was involved in the writing and reviewing of this work. KPJ was involved in study design and provided statistical support throughout the course of the study. UTK conceived and designed this study, was involved with analysis and interpretation and contributed to the writing of this manuscript. All authors have contributed and approved the final version of this manuscript.

\section{Acknowledgements}

We are grateful for the participation of general practice teams and their patients. Within Keele University, special acknowledgements are given to the survey, network, administration and management teams who supported the study. UTK was funded by a National Institute for Health Research (NIHR) Post-Doctoral Fellowship (grant no. PAS/PDA/03/07/035) and by a Royal Society International Short Visit grant and the West Midlands Advantage scheme. We thank Peter Croft and Rhian Hughes for their advice and support.

Received: 2 July 2012 Accepted: 1 August 2012

Published: 3 September 2012

\section{References}

1. Wolff JL, Starfield B, Anderson G: Prevalence, expenditures, and complications of multiple chronic conditions in the elderly. Arch Intern Med 2002, 162:2269-76.

2. Department of Health: National service framework for coronary heart disease. London: DoH; 2000.

3. Roland M, Coulter A: Hospital referrals. Oxford: OUP; 1992.

4. Greenfield S, Aronow HU, Elashoff RM, et al: Flaws in mortality data. The hazards of ignoring comorbid disease. JAMA 1988, 260:2253-2255.

5. Starfield B, Lemke KW, Bernhardt T, et al: Comorbidity: implications for the importance of primary care in 'case' management. Ann Fam Med 2003, $1: 8-14$

6. Starfield B: New paradigms for quality in primary care. Br J Gen Pract 2001, 51:303-9.

7. Kadam UT: Clinical comorbidity in older patients with osteoarthritis in the primary care population. PhD thesis: Keele University; 2007.

8. McCormick A, Fleming D, Charlton J: Morbidity statistics from general practice. London: HMSO: Fourth national study 1991-2; 1995.

9. Asadi L, Packham C, Gray D: Is quality of life measurement likely to be a proxy for health needs assessment in patients with coronary artery disease? Health Qual Life Outcomes 2003, 1:50.

10. Surtees PG, Wainwright NW, Khaw KT, et al: Functional health status, chronic medical conditions and disorders of mood. Br J Psychiatry 2003, 183:299-303.

11. Rodríquez-Artalejo F, Guallar-Castillón P, Pascual CR, et al: Health-related quality of life as a predictor of hospital readmission and death among patients with heart failure. Arch Intern Med 2005, 165(11):1274-9.

12. Höfer S, Doering S, Rumpold G, et al: Determinants of health-related quality of life in patients with coronary artery disease. Eur J Cardiovasc Prev Rehabil 2006, 13(3):398-406.

13. Bardage C, Isacson DG: Hypertension and health-related quality of life: an epidemiological study in Sweden. J Clin Epidemiol 2001, 54(2):172-81.

14. Kang YR: Relation of atrial arrhythmia-related symptoms to health-related quality of life in patients with newly diagnosed atrial fibrillation: a community hospital-based cohort. Heart Lung 2006, 35(3):170-7.

15. Spertus JA, McDonell M, Woodman CL, et al: Association between depression and worse disease-specific functional status in outpatients with coronary artery disease. Am Heart J 2000, 140(1):105-10.

16. Rahimi AR, Spertus JA, Reid KJ, et al: Financial barriers to health care and outcomes after acute myocardial infarction. JAMA 2007, 297:1063-72.

17. Faller $\mathrm{H}$, Störk S, Schowalter M, et al: Is health-related quality of life an independent predictor of survival in patients with chronic heart failure? J Psychosom Res 2007, 63:533-8.

18. Adamson J, Lawlor DA, Ebrahim S: Chronic diseases, locomotor activity limitation, and social participation in older women: cross-sectional survey of British Women's Heart and Health Study. Age Ageing 2004 33:293-8.

19. Yelin E, Callahan LF: The economic cost and social and psychological impact of musculoskeletal conditions. National Arthritis Data Work Groups, Arthritis Rheum 1995, 38:1351-1362.

20. Frankel S, Eachus J, Pearson N, et al: Population requirement for primary hip-replacement surgery: a cross-sectional study. Lancet 1999, 353:1304-1309.

21. Eccles M, Freemantle N, Mason J: North of England evidence based guideline development project: summary guideline for non-steroidal anti-inflammatory drugs versus basic analgesia in treating the pain of degenerative arthritis. The North of England Non-Steroidal AntiInflammatory Drug Guideline Development Group. BMJ 1998, 317:526-530.

22. Schellevis FG, van der Velden J, van de Lisdonk E, et al: Comorbidity of chronic diseases in general practice. J Clin Epidemiol 1993, 46:469-73. 
23. Kadam UT, Jordan K, Croft PR: Clinical comorbidity in patients with osteoarthritis: a case-control study of general practice consulters in England \& Wales. Ann Rheum Dis 2004, 63:408-14

24. Kadam UT, Croft PR: Clinical comorbidity in osteoarthritis: associations with physical function in older patients in family practice. J. Rheumatol 2007, 34:1899-904

25. Greenberg JD, Bingham CO 3rd, Abramson SB, et al: Effect of cardiovascular comorbidities and concomitant aspirin use on selection of cyclooxygenase inhibitor among rheumatolgists. Arthritis Rheum 2005 53:12-7.

26. Singh G, Miller JD, Lee FH, et al: Prevalence of cardiovascular disease risk factors among US adults with self-reported osteoarthritis: data from the third National Health and Nutrition Examination Survey. Am J Manag Care 2002, 8:\$383-\$391.

27. Ettinger $W H$, Davis MA, Neuhaus JM, et al: Long-term physical functioning in persons with knee osteoarthritis from NHANES. I: Effects of comorbid medical conditions. J Clin Epidemiol 1994, 47:809-15.

28. Lin EH, Katon W, Von Korff M, et al: Effect of improving depression care on pain and functional outcomes among older adults with arthritis: a randomized controlled trial. JAMA 2003, 290:2428-9.

29. van den Akker M, Buntinx F, Metsemakers JF, et al: Multimorbidity in general practice: prevalence, incidence, and determinants of co-occurring chronic and recurrent diseases. J Clin Epidemio/ 1998, 51:367-75.

30. Fortin M, Bravo G, Hudon C, et al: Prevalence of multimorbidity among adults seen in family practice. Ann Fam Med 2005, 3:223-8.

31. Smeeth L, Thomas SL, Hall AJ, et al: Risk of myocardial infarction and stroke after acute infection or vaccination. N Engl J Med 2004, 16:2611-8.

32. Kadam UT, Jordan K, Croft PR: Clinical comorbidity was specific to disease pathology, psychologic distress, and somatic symptom amplification. J Clin Epidemiol. 2005, 58:909-17.

33. Michelson $\mathrm{H}$, Bolund $\mathrm{C}$, Brandberg Y: Multiple chronic health problems are negatively associated with health related quality of life (HRQoL) irrespective of age. Qual Life Res 2000, 9:1093-104

34. Starfield B, Lemke KW, Herbert R, et al: Comorbidity and the use of primary care and specialist care in the elderly. Ann Fam Med 2005, 3:215-22.

35. Dunn KM, Jordan K, Croft PR: Characterizing the course of low back pain: a latent class analysis. Am J Epidemiol 2006, 163:75-61.

36. Lloyd-Jones DM, Larson MG, Beiser A, et al: Lifetime risk of developing coronary heart disease. Lancet 1999, 353:89-92.

37. Lloyd-Jones DM, Wilson PW, Larson MG, et al: Lifetime risk of coronary heart disease by cholesterol levels at selected ages. Arch Int Med 2003, 163:1966-72.

38. Lloyd-Jones DM, Larson MG, Leip EP, et al: Lifetime risk for developing congestive heart failure: the Framingham Heart Study. Circulation 2002, 106:3068-72.

39. Harding A, Stuart-Buttle C: The development and role of the Read Codes JAHIMA 2008, 69:34-38.

40. British Medical Association and Royal Pharmaceutical Society of Great Britain: British National Formulary. London: British National Formulary, British Medical Association/The Pharmaceutical Press; 2008.

41. Pringle M, Ward P, Chilvers C: Assessment of the completeness and accuracy of computer medical records in four practices committed to recording data on computer. Br J Gen Pract 1995, 45:537-41.

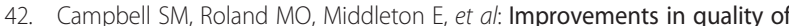
clinical care in English general practice 1998-2003: Iongitudinal observational study. BMJ 2005, 331:1121.

43. Ware JE Jr, Kosinski M, Keller SD: A 12-Item Short-Form Health Survey: construction of scales and preliminary tests of reliability and validity. Med Care 1996, 34:220-233.

44. Wendel-Vos WGC, Schuit JA, Saris WHM, et al: Reproducibility and relative validity of the short questionnaire to assess health-enhancing physical activity. J Clin Epidemiol 2003, 56:1163-1169.

45. Zigmond A, Snaith RP: The Hospital Anxiety and Depression Scale. Acta Psychiatr Scand 1983, 67:361-370

46. Dougherty CM, Dewhurst T, Nichol WP, et al: Comparison of Three Quality of Life Instruments in Stable Angina Pectoris: Seattle Angina Questionnaire, Short Form Health Survey (SF-36), and Quality of Life Index-Cardiac Version III. J Clin Epidemiol 1998, 51:569-575.
47. Spertus JA, Peterson ED, Conard MW, et al: Monitoring clinical changes in patients with heart failure: A comparison of methods. Am Heart J 2005, 150:707-15

48. Rose GA, Blackburn H: Cardiovascular survey methods. Geneva: WHO; 1996.

49. Lok NS, Lau CP: Prevalence of palpitations, cardiac arrhythmias and their associated risk factors in ambulant elderly. Int J Cardiol 1996, 54:231-6.

50. Nazareth I, Landau S, Yardley L, et al: Patterns of presentations of dizziness in primary care-a cross-sectional cluster analysis study. J Psychosom Res 2006, 60:395-401.

51. Perruccio AV, Stefan Lohmander L, Canizares $M$, et al: The development of a short measure of physical function for knee OA KOOS-Physical Function Shortform (KOOS-PS) - an OARSI/OMERACT initiative. Osteoarthritis Cartilage 2008, 16:542-550.

52. Davis AM, Perruccio AV, Canizares M, et al: The development of a short measure of physical function for hip OA HOOS-Physical Function Shortform (HOOS-PS): an OARSI/OMERACT initiative. Osteoarthritis Cartilage 2008, 16:551-9.

53. Lacey RJ, Lewis M, Jordan K, et al: Interrater reliability of scoring of pain drawings in a self-report health survey. Spine 2005, 30:E455-8.

54. Cella D, Yount $S$, Sorensen M, et al: Validation of the Functional Assessment of Chronic Illness Therapy Fatigue Scale relative to other instrumentation in patients with rheumatoid arthritis. J Rheumato/ 2005 32:811-819

55. Hays RD, Martin SA, Sesti AM, et al: Psychometric properties of the Medical Outcomes Study Sleep measure. Sleep Med 2005, 6:41-4.

56. Kadam UT, Jordan K, Croft PR: A comparison of two consensus methods in a single professional group showed the same outcomes. J Clin Epidemiol 2006, 59:1169-73.

57. Kadam UT, Schellevis FG, van der Windt DAWM, et al: Morbidity severity classifying routine consultations from English and Dutch general practice indicated physical health status. J Clin Epidemiol 2008, 61:386-93.

58. Department for Communities and Local Government: The English Indices of Deprivation. 2007. Accessed 11th June; 2008. http://www.communities.gov. uk/publications/communities/indiciesdeprivation07.

59. France EF, Wyke S, Gunn JM, et al: Multimorbidity in primary care: a systematic review of prospective cohort studies. Br J Gen Pract 2012 62:297-307.

doi:10.1186/1472-6963-12-295

Cite this article as: Prior et al.: Comorbidity Cohort (2C) study: Cardiovascular disease severity and comorbid osteoarthritis in primary care. BMC Health Services Research 2012 12:295.

\section{Submit your next manuscript to BioMed Central and take full advantage of:}

- Convenient online submission

- Thorough peer review

- No space constraints or color figure charges

- Immediate publication on acceptance

- Inclusion in PubMed, CAS, Scopus and Google Scholar

- Research which is freely available for redistribution 